\title{
CONFLICTIVIDAD LABORAL EN UN PUERTO TRANSFRONTERIZO: ARICA, 2003-2004*
}

\author{
LABOR CONFLICT IN A CROSS-BORDER PORT: ARICA, 2003-2004
}

\author{
Camila Álvarez Torres ${ }^{* *}$ y Camilo Santibáñez Rebolledo ${ }^{* * *}$
}

\begin{abstract}
Basado en la conflictividad laboral generada por la concesión del puerto de Arica (2003-2004), este artículo examina el comportamiento de los diferentes actores chilenos y bolivianos involucrados en el circuito comercial transfronterizo. Respectivamente: el gobierno central de Chile, los estibadores, el empresariado portuario y el empresariado local; el gobierno central de Bolivia, los camioneros y el empresariado mercantil. Según se argumenta, el poder estructural de circulación ejercido por los estibadores en el tráfico comercial generó alineamientos que evidenciaron la articulación transfronteriza acerca del comportamiento de clase y la nacionalidad de estos actores, develando el relacionamiento asimétrico en que opera la interdependencia económica de la región.

Palabras claves: Conflicto laboral, trabajo portuario, concesión portuaria, región transfronteriza, Arica.
\end{abstract}

Based on the labor conflict generated by the concession of the port of Arica (2003-2004), this paper examines the behavior of the different Chilean and Bolivian actors involved in the cross-border commercial circuit. Respectively: the central government of Chile, the dockers, the port entrepreneur and the local entrepreneur; the central government of Bolivia, truckers and commercial entrepreneurs. As argued, the structural power of circulation exercised by dockers over commercial traffic generated alignments that evidenced cross-border articulation on class behavior and the nationality of these actors, revealing the asymmetric relationship in which the economic interdependence of the region operates.

Key words: Labor conflict, dock work, port concession, cross-border region, Arica.

\section{Introducción}

El actual carácter transfronterizo del puerto de Arica es consecuencia del enfrentamiento bélico protagonizado por las repúblicas de Bolivia, Chile y Perú en 1879-1884. Concretamente, de la ocupación militar chilena de esta ciudad, perteneciente a Perú hasta 1880, y del Tratado que consagró la mediterraneidad de Bolivia en 1904, en cuyo resarcimiento fue dictaminado el derecho a perpetuidad para el libre tránsito comercial hacia el Pacífico y la construcción del Ferrocarril Arica-La Paz para garantizar su ejercicio (Diario oficial, 27 de marzo de 1905; Dilla 2018; Donoso 2019).

Si bien los camiones han desplazado al ferrocarril como el principal transporte de la carga desde entonces, dicho Tratado implica que las mercancías bolivianas conformen alrededor del $80 \%$ del total de la carga movilizada por este puerto en la actualidad (Empresa Portuaria de Arica 2019). Lo que condiciona la operación del terminal como un dispositivo intermodal rígido, que tiende a resentir, además, las tensiones consulares entre Bolivia y Chile.

En estas circunstancias $-\mathrm{y}$ en vísperas del centenario del mismo Tratado-, los gobiernos chilenos iniciaron un proceso de licitación de los principales terminales marítimos del país a empresas privadas. En 1999 se iniciaron los trámites en Valparaíso, San Antonio, San Vicente, Iquique y Arica, lo que desató la protesta de los estibadores y funcionarios portuarios en defensa de sus puestos de trabajo. Durante el año siguiente, los adjudicatarios privados iniciaron sus contratos en los primeros cuatro puertos mencionados y, forzado por los daños económicos de los paros, el gobierno respondió a las reivindicaciones obreras mediante diferentes tipos de indemnizaciones (Ministerio de Obras Públicas, Transportes y Telecomunicaciones 2005; Biblioteca del Congreso Nacional de Chile 2014).

\footnotetext{
* $\quad$ Este artículo es resultado del Proyecto FONDECYT Regular N¹190133 "La intermediación urbano-portuaria en un contexto transfronterizo: Arica (2008-2018)".

** Instituto de Estudios Internacionales (INTE), Universidad Arturo Prat. Doctoranda CONICYT en Centre d'Estudis Sociològics sobre la Vida Quotidiana i el Treball (QUIT), Institut d'Estudis del Treball (IET), Universitat Autònoma de Barcelona. Barcelona, España. Correo electrónico: cami.alvarez.to@gmail.com

*** Instituto de Estudios Internacionales (INTE), Universidad Arturo Prat. Doctorando CONICYT, Departamento de Historia, Universidad de Santiago de Chile. Santiago, Chile. Correo electrónico: sntibaez@gmail.com
} 
En el puerto de Arica, en cambio, la licitación no concitó oferentes. Según la prensa capitalina chilena, "las empresas concesionarias no estaban dispuestas a invertir en un puerto con altos costos de infraestructura [dadas] las características particulares que este terminal tiene". Refiriéndose con ello al almacenamiento gratuito de las exportaciones bolivianas hasta por sesenta días y un año en el caso de las importaciones; una franquicia que, en la proximidad del proceso de licitación, implicaba alrededor de US\$ 3 millones anuales de subsidio estatal (El Mercurio, 9 de octubre de 2000 y 27 de enero de 2004).

Este fracaso implicó la postergación y el mejoramiento de las condiciones de la concesión. El nuevo anuncio gubernamental, realizado el 2003, procuró garantizar que el bodegaje de las cargas bolivianas seguiría siendo financiado por el Estado, e igualmente redujo la inversión exigida en infraestructura de US\$ 34 a US\$ 17 millones (Diario Financiero, 23 de marzo del 2004). Al igual que en 1999 el anuncio concitó la reacción obrera y el proceso de licitación estuvo marcado por dos huelgas relevantes en 2003 y 2004.

La particularidad en este caso fue que, además de los trabajadores, también la autoridad local y los transportistas bolivianos rechazaron tempranamente la licitación (El Mercurio, 11 de agosto de 2003), lo que produjo un ordenamiento privativo de estos conflictos en relación con los anteriores. Por una parte, se alineó el interés privatizador del gobierno central chileno con las empresas concesionarias y los exportadores bolivianos; por otra, se alinearon los intereses de los estibadores ariqueños, del empresariado local, del alcalde de ambos, de los camioneros bolivianos y de las Cámaras Departamentales de Transportes de este último país; concitando circunstancialmente, además, el respaldo de su gobierno central.

El objetivo de este artículo es explorar esta particularidad, examinando la forma en que la interdependencia económica de la región prefiguró las posiciones y el comportamiento de los actores involucrados en las huelgas de 2003-2004. La hipótesis plantea que estas huelgas, originadas en el antagonismo laboral entre obreros y empresarios portuarios, implicaron económicamente a otros actores partícipes del circuito regional, volviéndolos políticamente determinantes para el desenlace de los conflictos; cuestión que constituye y devela el carácter transfronterizo del puerto de Arica.
Para desarrollar esta hipótesis, y tras la siguiente nota metodológica, el subtítulo a continuación plantea algunas consideraciones teóricas para el estudio de la conflictividad laboral en un puerto de estas características. El subsiguiente resume los acontecimientos huelguísticos mencionados, denotando los alineamientos regionales propuestos, y el último ofrece una interpretación de dichos alineamientos. Finalmente, las conclusiones resaltan el potencial analítico que las huelgas pueden reportar al estudio de las regiones transfronterizas.

\section{Metodología}

La evidencia empírica presentada en este artículo fue obtenida de la revisión y el cotejo de periódicos capitalinos de circulación nacional en Bolivia ( $E l$ Diario) y Chile (El Mercurio y La Segunda) durante el lustro 1999-2004. Este seguimiento se centró en el comportamiento de los actores bolivianos y chilenos involucrados en las huelgas de 2003 y 2004. Respectivamente: el Estado de Chile, el empresariado portuario chileno, el empresariado local y los estibadores ariqueños; el Estado de Bolivia, el empresariado mercantil boliviano y los camioneros del mismo país. El procesamiento de esta información se basó, primero, en reconstruir sincrónicamente ambos conflictos (2003 y 2004); $\mathrm{y}$, segundo, en establecer los comportamientos de dichos actores de forma diacrónica, buscando patrones que permitan interpretar sus respectivos alineamientos.

Sin asumir supeditación alguna, esta exploración -basada, como se indicó, en prensa capitalina- espera brindar un marco de referencia para investigaciones fundadas en fuentes locales. No por suponer que su complemento garantice la compleción documental de los fenómenos estudiados, sino por la dinámica que ambos planos entablan y que los respectivos medios de prensa registran. Lo que debe leerse, también, como una declaración de las limitaciones de las fuentes aquí empleadas.

\section{Puertos, conflictividad y (trans)frontera}

Aunque la conflictividad laboral en los puertos y la condición transfronteriza han recibido bastante atención durante los últimos años, la relación entre ambos asuntos no ha suscitado el mismo interés. Por una parte, los estudios pertinentes a los terminales marítimos han abordado la organización del trabajo, 
las estrategias sindicales de los obreros y la forma en que estos emplean el poder que les brinda su posición estructural en la circulación de mercancías (Álvarez 2019; Fox-Hodess y Santibáñez 2020; Santibáñez 2016, 2017, 2018 y 2019; Santibáñez y Gaudichaud 2017). Por otra, los fenómenos transfronterizos se han concentrado en el relacionamiento político de los actores, en los circuitos económicos y en los procesos de movilidad, incluyendo la precariedad de la fuerza de trabajo circular (Contreras et al. 2017; Dilla y Álvarez 2018 y 2019; Jiménez et al. 2019; Ovando y González 2016; Tapia et al. 2017).

Sin embargo, su eventual combinación permite atisbar un cruce analítico promisorio. Principalmente porque los estibadores cuentan con un repertorio de acción colectiva que incluye el bloqueo del tráfico mercantil como forma recurrente de protesta (Santibáñez 2016). Lo que, en un puerto transfronterizo como Arica, implica la presión del incumplimiento estatal para con las cargas bolivianas, cuya repercusión afecta una relación bilateral friccionada y diplomáticamente resquebrajada (Correa y García 2012; Ross y Leiva 2017).

Adoptando el marco analítico de los "recursos de poder" (Schmalz 2017; Varela 2014; Wright 2000), esta capacidad disruptiva de los estibadores constituye su "poder estructural de circulación". Cuya relevancia se resume en que la posición que estos trabajadores ocupan en el circuito productivo les permite interrumpir súbitamente el tránsito de las mercancías, provocando un daño económico de gran alcance, cuyo descalabro termina forzando a sus contrapartes a negociar en su favor.

En el caso chileno, los estibadores han acostumbrado a esgrimir el poder estructural de circulación para revertir el escaso poder institucional de los trabajadores en general (Santibáñez y Gaudichaud 2017). Su recurrencia en los últimos años, de hecho, puede estimarse con base en una estadística simple: en el lustro 2010-2014, los puertos chilenos registraron prácticamente la misma cantidad de días de paro que en todos los puertos restantes del continente (El Mercurio, 21 de marzo de 2014).

Sin embargo, la prolongación de los conflictos laborales en los principales puertos exportadores durante la misma década, así como sus muy distintos desenlaces, sugieren que la fórmula simplificada de la "posición estratégica" (Womack 2007) debe ser examinada más acuciosamente. En primer término, prestando atención a su imprescindible basamento asociativo, así como a la relevancia del poder social que impide que su relevancia estructural se torne en su contra, por ejemplo, represivamente (Fox-Hodess y Santibáñez 2020). Pero también prestando atención a las particularidades geopolíticas que no pueden soslayarse bajo la generalidad de las categorías.

En estos términos, este artículo asume que las huelgas de estibadores en Arica comportan una buena posibilidad para la conjunción de los estudios mencionados, porque su capacidad disruptiva adquiere una connotación distinta al afectar una economía de "región transfronteriza" (Dilla y Breton 2018). Especialmente si esa disrupción es ejercida por obreros de un país diferente al de las mercancías cuyo tráfico interrumpen; en un puerto, como se dijo, cuyo propósito radica en compensar la mediterraneidad que el primero de estos países le infligió al segundo.

A este respecto, es importante señalar que diferentes investigadores han reparado en el hecho de que las regiones transfronterizas latinoamericanas tienden a asumir relacionamientos asimétricos y conflictivos, cuyas articulaciones -sobre todo en fronteras con alta interacción- están amparadas en una intrincada interdependencia económica (Dilla 2015, 2016, 2018; Dilla y Breton 2018; Keohane y Nye 1988). Cuestión que afecta en un modo igualmente complejo a los actores que encarnan dichos relacionamientos, rigiendo sus comportamientos en formas que no se deducen de sus respectivas nacionalidades, meramente, sino de los roles específicos que adquieren y ejercen en dicha interdependencia regional. Lo que estremece los relacionamientos institucionales y adquiere, por tanto, un rango político particular.

En un puerto como el de Arica, en consecuencia, una huelga puede develar los diferentes planos implicados en la configuración regional transfronteriza de la que forma parte, así como su relacionamiento asimétrico.

\section{Las huelgas de 2003-2004 en el puerto de Arica}

Desde 1998, el puerto de Arica es administrado por un ente público denominado Empresa Portuaria de Arica (EPA). Como ocurrió en los otros puertos estatales, dicho ente fue creado con motivo de la reestructuración de la Empresa Portuaria de Chile (EMPORCHI) con el objeto de velar por los procesos de licitación y concesión de los frentes de atraque, e igualmente para administrar la infraestructura 
no licitada y los terrenos extraportuarios (Carillo y Santander 2005). Con estas atribuciones, y tras el fallido primer intento del 2000, la EPA insistió en la licitación el 2003, figurando como único interesado el consorcio Terminal Puerto Arica (TPA) conformado por los principales operadores portuarios chilenos reunidos de forma inédita: el grupo Ultramar, controlado por la familia Von Appen, con el 40\% de la propiedad; Empresas Navieras, de Urenda, con el 25\%; SAAM, del grupo Claro, con el 15\%; y Ransa, propiedad del empresario peruano Dionisio Romero -asociado al empresariado chileno en la administración de Matarani, Perú-, con el 20\% restante (La Tercera, 3 y 8 de agosto de 2004; La Segunda, 4 de agosto de 2004). Este grupo se declaró adjudicatario e inició su administración el 2004.

Entre el anuncio de licitación y su resultado se generaron varios conflictos laborales derivados de la concesión; dos de estos cobraron carácter de huelgas y tuvieron un impacto significativo en el tráfico mercantil y, por esta razón, en la economía regional. Los subtítulos siguientes examinan ambos conflictos, ocurridos, respectivamente, en el 2003 y 2004.

\section{La huelga del 2003}

En el 2003 se produjeron tres huelgas en el puerto de Arica. Las dos primeras fueron en exigencia de una red gubernamental de protección social frente a la licitación; demanda que, al ser programada para su resolución, abrevió las movilizaciones a cuestión de horas. La tercera huelga, en cambio, iniciada durante la segunda mitad de octubre, demandó "una tarifa de turno digna antes que se licite el puerto" (La Segunda, 27 de octubre de 2003). Lo que generó la resistencia patronal y prolongó la paralización durante toda una semana, provocando un atochamiento de casi 400 camiones y más de 100 vagones ferroviarios con alrededor de 20 mil toneladas de carga entre exportaciones e importaciones (El Mercurio, 30 de octubre de 2003).

En el inicio de este paro, las agencias navieras, la Cámara de Comercio local, los representantes de los transportistas y hasta el Consulado General de Bolivia en Arica se reunieron para presentar un recurso de amparo económico, solicitar la aplicación de la Ley de Seguridad Interior al Estado chileno y, no obstante aquello, amenazar con un paro empresarial. Sin embargo, el gobierno chileno rechazó la petición, desentendiéndose de su responsabilidad en la mantención del flujo comercial boliviano, aduciendo que el problema concernía a privados (El Mercurio, 25 de octubre de 2003; La Segunda, 27 de octubre de 2003; El Diario, 29 de octubre de 2003).

De forma simultánea, dirigentes sindicales de otros puertos chilenos ofrecieron un "acuerdo de solidaridad mutua" a los estibadores locales, proponiendo un boicot "en todos los puertos en que recalen los buques atendidos por las navieras de Arica" (El Mercurio, 28 de octubre de 2003). Cuestión que elevó la preocupación del empresariado chileno, debido a la proximidad de la temporada de exportación de la fruta, la carga perecible más importante del país (El Mercurio, 28 de octubre de 2003; Diario Financiero, 28 y 29 de octubre de 2003).

En medio de esta belicosidad, sin embargo, el destrabe se provocó por el "súbito giro de los representantes de los transportistas bolivianos y de los propios empresarios ariqueños", quienes dejaron de responsabilizar a los estibadores, "para acusar directamente a [una empresa nacional] de ser la responsable -por su intransigencia- de las graves consecuencias provocadas por el paro" ( $E l$ Mercurio, 30 de octubre de 2003).

Según consignó la prensa capitalina en Chile:

Los actores afectados económicamente por estas paralizaciones, la tercera en lo que va del año, dejaron de lado su tradicional actitud pasiva y ejercieron una presión que resultó ser decisiva para el desenlace. Unos ochenta camioneros bolivianos -que desde hace días habitaban en los sitios portuarios, durmiendo en sus camiones- se congregaron ayer en los accesos del recinto para exigir que se permitiera descargar sus vehículos y sacarlos del puerto, reclamando a su Cancillería que exija el respeto del libre tránsito. Sorpresivamente, los representantes de las Cámaras Departamentales de Transportes de La Paz y Oruro y de empresas de transporte internacional de Bolivia dejaron de descalificar a los dirigentes portuarios para -junto a ellos- ir a las oficinas de [la empresa] Ultramar y encarar a su agente. Similar actitud asumió el presidente de la Asociación de Industriales de Arica [quien 
terminó] participando junto a los líderes portuarios en una improvisada conferencia de prensa (El Mercurio, 29 de octubre de 2003).

La resolución del conflicto se basó en el acuerdo de poco más de US\$20 por turno a los trabajadores eventuales, elevando los menos de US\$ 19 que recibían por atención a buques y los US\$ 13 a camiones. La red de protección social con motivo de la licitación que había provocado los dos paros previos, sin embargo, se mantuvo como asunto pendiente.

Concluida la huelga, las críticas del gobierno boliviano se enfocaron en la nula consulta respecto de la licitación, acusando la vulneración del Tratado de 1904 (El Diario, 29 de octubre de 2003; El Mercurio, 30 de octubre de 2003). El asunto escaló rápidamente y para febrero del 2004 el mismo gobierno amenazó con llevar el asunto a organismos y arbitraje internacionales. Sin embargo, el empresariado boliviano se mostró indiferente a la política licitadora, toda vez que no cambiara las condiciones comerciales en vigencia (La Nación, 11 de febrero de 2004). Cuestión que la licitación en efecto resguardaba.

El entonces alcalde de Arica, en tanto, perteneciente a la coalición política de derecha y opositora al gobierno central, fue enfático en promover la participación boliviana en la licitación, argumentando que los terminales debían ser administrados por los dueños de la carga. "No quiero que esta empresa quede en manos de entidades chilenas que son dueñas de todos los puertos del país", señaló. Pues, en su interpretación, ello iba a significar convertirlo "en un puerto menor, es decir, que se dedique solamente a sacar minerales y soya" (La Segunda, 12 de febrero de 2004). Lo que afectaría directamente los réditos que la ciudad podía obtener del puerto.

Como fuere, lo cierto es que las materias postergadas tras la resolución de la huelga prefiguraban un año turbulento. Especialmente considerando el desentendimiento estatal frente al conflicto y el modo en que las solidaridades tradicionales se habían conjugado con las menos tradicionales frente a la capacidad disruptiva del bloqueo obrero al tráfico comercial.

\section{La huelga del 2004}

En efecto, una segunda huelga de relevancia estalló medio año más tarde, en abril del 2004. Se prolongó por dos semanas y su principal motivo fue resolver las diferencias respecto de la indemnización ofrecida por el Estado a los estibadores que perdieran su trabajo a causa del proceso de licitación en curso. Concretamente: la "red de protección social" ideada por el gobierno implicaba pensiones de hasta US\$ 10.000 para la creación de microempresas, pero los trabajadores demandaban US\$32.000, además de la disminución del requisito de antigüedad para acceder a estos beneficios, de catorce a diez años (El Mercurio, 14 y 16 de abril de 2004; El Diario, 19 y 20 de abril de 2004).

Esta situación puso al gobierno chileno bajo fuego cruzado. Pues, basándose en la protesta obrera, el gobierno boliviano lo responsabilizó, nuevamente, por no garantizar el libre tránsito de las mercancías bolivianas, como establecía el Tratado centenario. Cuestión que le permitió insistir, además, en la necesidad de una "solución definitiva a su mediterraneidad" (El Diario, 17, 19 y 20 de abril de 2004; El Mercurio, 15 de abril de 2004).

Al tercer día de paro, con alrededor de doscientos camiones atochados en el puerto y seis buques sin atender-además de áreas económicas locales tan relevantes como la minería, el ensamblaje de vehículos y la industria pesquera afectadas-, los transportistas bolivianos solidarizaron con los estibadores en huelga (El Diario, 17 de abril de 2004). "Esta actitud es opuesta a la adoptada en paros anteriores", consignó la prensa chilena, obviando lo sucedido el 2003, "y es coherente con la posición planteada por el gobierno boliviano”. La Cámara Departamental de Transportes de Bolivia fue todavía más enfática, argumentando que, si el gobierno chileno no era capaz de controlar la situación, "menos lo [iba] a ser con el puerto licitado a un solo operador". Frente al resurgimiento de los anuncios de alegato internacional del gobierno boliviano, y en consonancia, los trabajadores ariqueños sentenciaron: "nos ayudaría", provocándose un maridaje circunstancial inquietante para el gobierno central chileno (El Mercurio, 16 y 18 de abril de 2004).

Este último gobierno, empero, se había reunido con los obreros a poco de iniciado el paro. Con los estibadores ariqueños, en principio, pero también con la organización que los respaldaba nacionalmente (La Segunda, 16 de abril de 2004). Por este motivo el gobierno central chileno se arrogó una tercera presión: la del empresariado portuario que les exigió no ceder al petitorio, toda vez que implicaría "[abrir] las puertas para que haya nuevos 
conflictos en la licitación de otros puertos en el futuro" (Diario Financiero, 19 de abril de 2004). La Intendencia, en aparente eco, ofreció resguardo policial a las cuadrillas de rompehuelgas que las empresas portuarias locales lograran reclutar, pero la convocatoria no consiguió adhesión (El Mercurio, 20 de abril de 2004).

Tras una semana de paro y duros enfrentamientos entre obreros y policías frente al acceso del puerto, el desenlace se precipitó de forma confusa. Cuando los transportistas bolivianos evaluaban el bloqueo de la frontera, el vocero de la organización nacional de trabajadores portuarios, Jorge Silva Berón, evidenció diferencias con los obreros ariqueños, reprobando su rechazo a la oferta gubernamental: "Para iniciar una microempresa [los obreros de Valparaíso] tuvieron que conformarse con alrededor de US\$9.000 y ahora la autoridad está ofreciendo más de US\$12.000", manifestó en la prensa nacional chilena, agregando que: "los trabajadores de Valparaíso con 40 años o más podían acceder a los beneficios, mientras que ahora esa barrera bajó a los 35 años" (El Mercurio, 18 de abril de 2004; La Segunda, 19 y 20 de abril de 2004). Lo que quebró las relaciones entre los estibadores locales y nacionales, despojando a los primeros de su posibilidad de extender su poder estructural de circulación a lo largo de la costa chilena.

No obstante esta fisura en el campo obrero, el gobierno central cedió a la demanda de rebajar la edad requerida, aumentando los cupos para la reconversión y resolviendo el paro (El Mercurio, 21 de abril de 2004). Según la prensa empresarial chilena, el tensionamiento a las ya "desgastadas relaciones chileno-bolivianas" y el perjuicio económico regional, hacían entendible "la celeridad con que las autoridades -no solo regionales, sino también nacionales-cedieron ante los estibadores para desactivar el conflicto". "Esto muestra", deducía el empresariado chileno, en oposición a la Cámara Departamental de Transportes boliviana, "los riesgos que conlleva el mantener actividades estratégicas en manos del Estado". Entendiendo por "estratégicas" aquellas "[actividades clave] por su importancia económica o su relevancia política"; dos características no excluyentes en el caso de este puerto (El Mercurio, 30 de abril de 2004).

En consecuencia, el poder estructural de circulación ejercido por los estibadores ariqueños había devenido en problema político incluso tras perder el respaldo del resto de los estibadores del país. Ello debido a su importancia económica regional, que, en circunstancias transfronterizas como las de Arica, donde el Estado es garante de su funcionamiento, la circulación de mercancías resulta primordial e indivisiblemente política.

\section{Alineamientos en una región transfronteriza}

Observados diacrónicamente, es obvio que el comportamiento de los actores involucrados frente al proceso de concesión del puerto de Arica fue inicialmente guiado por su posición laboral de clase: básicamente, la de los obreros portuarios frente a sus empleadores. La solidaridad prestada en ambas huelgas por los estibadores de otros puertos chilenos y la respuesta empresarial que ello concitó se encuadra en la misma dinámica.

No obstante, en lo concerniente a los otros actores regionales implicados -por efecto del poder estructural de circulación-, la alineación observada acusa el carácter indisociablemente transfronterizo del puerto ariqueño. Cuestión que define, en consecuencia, su particularidad.

En la huelga del 2003, por ejemplo, los obreros portuarios locales paralizaron contra una empresa nacional $\mathrm{y}$, al hacerlo, afectaron a los empresarios locales y también a los transportistas bolivianos que componían el circuito mercantil. Pese a esto, aquellos mismos empresarios y transportistas terminaron desbalanceando la situación en favor de los estibadores, respaldándolos contra la empresa chilena primero y, al menos en el caso de los camioneros bolivianos -patrones y trabajadores-, también contra el gobierno chileno en el conflicto del 2004.

Las distintas disposiciones del empresariado son sumamente significativas en lo relativo a la configuración regional. En el caso del empresariado local, el giro presentado durante la primera huelga -así como su tardanza en resolver dicho giro- sugiere una reacción correspondiente con su carácter de pequeños empresarios. Esto es: evidenciando su incapacidad financiera para soportar un paro prolongado, pero también una desvinculación con el gran empresariado portuario chileno.

En lo que a este último concierne, y considerando que la empresa protagonista en el paro del 2003 encabezó el posterior holding adjudicatario, es llamativo constatar su insistencia por obtener la concesión en medio de tanta hostilidad (El Mercurio, 20 de abril de 2004). A este respecto, es posible notar que el mismo concesionario reconoció luego que su inversión "[buscaba dar] una señal para que el 
gobierno siga licitando puertos" (Diario Financiero, 30 de agosto de 2004). Lo que significa que el gran empresariado chileno dispuso del puerto de Arica como palanca de asuntos nacionales, cuyo riesgo, en términos de conflictividad, era un mero costo de inversión. Un costo, es admisible insistir, demasiado alto para el pequeño empresariado local, vitalmente implicado en la dinámica regional.

El caso de las empresas bolivianas es todavía más complejo. En principio, la relación con su gobierno parece ilustrar la preeminencia de intereses políticos y económicos respectivamente; pero las circunstancias transfronterizas atentan contra la disociación general de estos campos e ilumina también sus disensos internos.

Por ejemplo, aunque ambos actores -empresarios y gobierno bolivianos- rechazaron el bloqueo obrero portuario del 2003, sus motivos particulares diferían de la concesión, que era el asunto de fondo. Mientras el gobierno boliviano manifestó una creciente preocupación y rechazo, la Cámara de Exportadores de Santa Cruz, el Departamento con mayor ímpetu exportador de Bolivia, argumentó que "la única alternativa viable y factible para el puerto de Arica [era] su entrega en concesión al sector privado". De hecho, consideraban tan importante lo referido al Tratado de 1904 como el énfasis que el gobierno chileno pusiera en comunicar que "[la concesión representaba] una herramienta efectiva para el desarrollo del comercio exterior boliviano". Motivo por el cual exigieron "auscultar a empresarios bolivianos -de preferencia relacionados con el sector exportador- para que participen en el proceso de licitación" (La Segunda, 20 de febrero de 2004; El Mercurio, 20 de febrero de 2004); una idea respaldada, es esencial recordar, por el alcalde de Arica.

Lo anterior, sin embargo, devela también la voluntad de la citada Cámara por involucrar a otros sectores del empresariado boliviano-deduciblemente reacios- con el ímpetu privatizador del gobierno chileno. Entre estos, se recordará, se hallaban las Cámaras Departamentales de Transportes bolivianas y su distancia con la licitación a un solo operador, pues temían el aumento de la frecuencia de los paros.

Finalmente, aunque el gobierno boliviano persistiera en apuntalar la "solución a su mediterraneidad" a partir de estos conflictos, su posición durante las huelgas varió desde la oposición al proceso de licitación hacia la exigencia de "garantías para que la presencia boliviana se [mantuviera] con el privado que administre el puerto" (El Diario, 19 de abril de 2004). Lo que denota el pragmatismo derivado de la dependencia exportadora boliviana en el relacionamiento regional -opuesta a la tozudez del gran empresariado chileno- y sugiere también su peso en las relaciones consulares.

\section{Conclusiones}

El estudio de las huelgas acontecidas en el puerto de Arica durante 2003-2004 permitió observar el ordenamiento que la condición transfronteriza y la interdependencia económica regional le impusieron a los diferentes actores involucrados en el tráfico comercial. También constatar el rango político que dicha condición e interdependencia le imprime a un conflicto de estas características. Pues, originadas en el antagonismo laboral, y expandidas por efecto del poder estructural de circulación de los estibadores, tales huelgas involucraron y enfrentaron no solo a las organizaciones gremiales, sino también a los respectivos gobiernos centrales. Cuestión que refrenda la hipótesis general.

Con la excepción del empresariado portuario chileno, escasamente afecto al ordenamiento local y regional, los comportamientos de los restantes actores regionales implicados exhiben una practicidad que pareciera supeditar la condición de clase y nacionalidad al funcionamiento del tráfico marítimo. Planteamiento que cabría reenfocar, subrayando que no existen condiciones de clase ni de nacionalidad que dicten lealtades generales por fuera de las circunstancias concretas en las que arraiga y se desarrolla la común operación de estos actores. Estas condiciones, como se observó, tienen un carácter específico que, en este caso, está indisociablemente constituido por la interdependencia transfronteriza regional antes descrita.

Metodológicamente, todo lo anterior pone de manifiesto que la conflictividad laboral en los puertos transfronterizos no solo ofrece un punto de entrada favorable para la observación de las interdependencias regionales y sus articulaciones asimétricas, sino también un modo de enfocar todo el asunto localmente. Es decir, asumiendo la relación geopolítica que entabla la región con los gobiernos centrales, sin reducirla a su mera supeditación administrativa.

Finalmente, los casos estudiados comportan una ruta relevante para observar cómo, dadas las circunstancias transfronterizas, el poder estructural de circulación de los obreros suscita su vinculación 
con actores capaces de ejercer el poder institucional del que ellos carecen. De hecho, las huelgas muestran que los estibadores pueden forzar este poder institucional de aquel modo y negociar el término de la disrupción del tráfico marítimo. Lo que no solo aumenta de modo circunstancial su poder asociativo y social, sino que refuerza, eventualmente, su poder estructural.

\section{Referencias Citadas}

Álvarez, C.

2019 "Repertorios de acción coletiva en el conflito laboral portuário: el caso de una federación portuária en el norte de Chile". En As Metamorfose do trabalho portuário. Mudanças em contextos de modernização, editado por F. Ferreira y C. M. Diéguez, pp. 193-220. Sociología e política, Sao Paulo.

Álvarez, C.

2019 "Comité de Integración y Desarrollo Fronterizo PerúChile: Aproximaciones al mundo social y empresarial en torno a la frontera". Si Somos Americanos 19(2):49-67.

Biblioteca del Congreso Nacional de Chile

2014 Paros portuarios: evaluación de los daños económicos. Departamento de Servicios Legislativos y Documentales, Unidad de Gestión de Conocimiento, 28 de enero.

Burkhalter, L.

1999 Privatización portuaria: Bases, alternativas y consecuencias, Comisión Económica para América Latina y El Caribe, Santiago.

Carrillo, I. y A. Santander

2005 "Modernización portuaria en Chile". Síntesis Tecnológica 2(2):63-69.

Contreras, Y., M. Tapia y N. Liberona

2017 "Movilidad y prácticas socioespaciales fronterizas entre Arica y Tacna. Del sentido de frontera a la transfrontericidad entre ciudades". Diálogo Andino 54:127-141.

Correa, V. y V. García

2012 "Aunque las aguas nos dividan: las relaciones chilenobolivianas y la construcción de una agenda común". Latinoamérica 54:75-110.

Dilla, H.

2015 "Los complejos urbanos transfronterizos en América Latina”. Revista de Estudios Fronterizos 16(31):15-38.

Dilla, $\mathrm{H}$.

2016 "Chile y sus fronteras: notas para una agenda de investigación”. Polis, Revista Latinoamericana 15(44):309-327.

Dilla, H.

2018 "Arica entre tres fronteras". Estudios Atacameños 57:221-238.

Dilla, H. y C. Álvarez

2018 "Arica/Tacna: Los circuitos económicos de un complejo urbano transfronterizo". Diálogo Andino 57:99-109.

Dilla, H. e I. Breton

2018 "Las regiones transfronterizas en América Latina". Polis 17(51):15-37.

Dilla, H. y C. Álvarez

2019 La vuelta de todo eso. Economía y sociedad en la frontera chileno/peruana: Complejo Urbano Transfronterizo Tacna/Arica. RIL, Santiago.

Dilla, H. y M. Figueroa

2019 "Escalas Econômicas e Regiões Transfronteiriças na América Latina". Espaço Aberto 9(2):7-22.
Donoso, C.

2019 "Reivindicaciones marítimas bolivianas durante la Guerra del Pacífico". Estudios Atacameños 62:143-161.

Empresa Portuaria de Arica

2019 Memoria Integrada 2018. Arica.

Fox-Hodess, K. y C. Santibáñez

2020 "The Social Foundations of Structural Power: Strategic Position, Worker Unity and External Alliances in the Making of the Chilean Dockworker Movement". Global Labour Journal 11(3):222-238.

Jiménez, R., P. Bachmann y N. Loza

2019 "Ferias informales y migración laboral comercial. Apuntes para el debate del corredor fronterizo peruanochileno". Estudios Fronterizos 20:E037.

Keohane, R. y J. Nye

1988 Poder e interdependencia. La política mundial de la transición. Grupo Editor Latinoamericano, Buenos Aires.

Ministerio de Obras Públicas, Transportes y Telecomunicaciones 2005 Sistema Portuario en Chile. Santiago.

Ovando, C. y S. González

2016 "Algunas expresiones de pluralismo diplomático chileno hacia Bolivia y Perú vistas desde el Norte Grande". En Relaciones transfronterizas y paradiplomacia en América Latina. Aspectos metodológicos y estudios de casos, editado por S. González, N. Cornago y C. Ovando, pp. 91-105. RIL, Santiago.

Ross, C. y S. Leiva

2017 "La política de Chile hacia Bolivia, 1990-2009. Ni coordinación política, ni cooperación económica”. Estudios Políticos 50:17-41.

Santibáñez, C.

2016 "Posiciones estratégicas y fuerza obrera: Apuntes en torno a un ciclo huelguístico de los estibadores del salitre (Chile, 1916-1923)". Izquierdas 30:188-214.

Santibáñez, C.

2017 "Los trabajadores portuarios chilenos y la experiencia de la eventualidad: Los conflictos por la redondilla en los muelles salitreros (1916-1923)". Historia 50(2):699-728.

Santibáñez, C.

2018 "La IWW y el movimiento obrero en Chile: El caso de los obreros portuarios nortinos (1919-1923)". Diálogo Andino 55:19-28.

Santibáñez, C.

2019 "Comunidades obreras portuarias y propensión a la huelga: Iquique, 1923”. Avances Del Cesor VXI(21):161-174.

Santibáñez, C. y F. Gaudichaud

2017 "Los obreros portuarios y la idea de "posición estratégica' en la postdictadura chilena (2003-2014)". En Trabajadoras y trabajadores. Procesos y acción sindical en el neoliberalismo chileno (1979-2017), editado por J. Ponce, C. Santibañez y J. Pinto, pp. 301-332. América en Movimiento, Valparaíso. 
Tapia, M., Liberona, N. y Contreras, Y.

2017 "El surgimiento de un territorio circulatorio en la frontera chileno-peruana: estudio de las prácticas socioespaciales fronterizas". Revista de Geografía Norte Grande 66: 117-141.

Varela, $P$.

2014 "Estado y sindicatos en la Argentina post-devaluación. El retorno del debate estratégico". Critica Marxista 38:119-202.
Womack, J.

2007 Posición estratégica y fuerza obrera. Hacia una nueva historia de los movimientos obreros. Fondo de Cultura Económica, Fideicomiso Historia de las Américas, Colegio de México, México.

Wright, E. O.

2000 "Working-class power, capitalist-class interest, and class compromise". American Journal of Sociology 105(4):957-1002. 